\title{
pH dependent efflux of methamphetamine derivatives and their reversal through human Caco-2 cell monolayers
}

\author{
Andrew Crowe* and Susanna Diep
}

School of Pharmacy, Curtin University of Technology. Perth, Western Australia.

*Correspondence and reprints: Dr. A. Crowe, Curtin University of Technology, School of Pharmacy, GPO Box U1987, Western Australia, 6845. Telephone: (618) 9266 3423; fax: (618) 9266 2769; email: A.P.Crowe@curtin.edu.au. 


\section{Abstract}

The purpose of this study was to investigate possible efflux mechanisms involved in amphetamine derivative transport such as for 3,4-methylenedioxymethamphetamine (MDMA), 3,4methylenedioxyethylamphetamine (MDEA), para-methoxyamphetamine (p-MA), dexamphetamine and pseudoephedrine, especially across $\mathrm{pH}$ gradients that exist in intestinal or kidney transport. This was determined using our Caco-2 subclone, CLEFF9. Transport of the amphetamine derivatives were evaluated at $\mathrm{pH}$ 7.4 and $\mathrm{pH}$ 6/7.4 \pm efflux inhibitors. $\mathrm{Na}^{+}-\mathrm{H}^{+}$transporter inhibition via carbonyl cyanide-4-trifluoromethoxy phenylhydrazone (FCCP), and metabolic inhibition using Naazide and Na-orthovanadate were also conducted, as well as using noradrenalin, adrenalin and other inhibitors of a range of carrier mediated transport systems such as histamine, organic cation transporters and dopamine carrier systems, . At pH 7.4, the rate of transport for dexamphetamine, pseudoephedrine and MDMA in both apical to basolateral and reverse directions were all very rapid, confirming extensive passive diffusion at systemic $\mathrm{pH}$. However, creating a pH 6.0/7.4 gradient showed marked increase in basolateral to apical transport of all amphetamines tested, with dexamphetamine, MDEA, MDMA and p-MA having a net efflux ratio of around 16, 14, 13 and 11 respectively and this was not reversed with P-glycoprotein inhibitors. Azide, FCCP, adrenalin, noradrenalin and reserpine were able to reduce the efflux by 2 to 3 fold, although tetraethylammonium could not. This suggested that extraneuronal monoamine transporters (hEMT) could be involved. This data suggests elevated endogenous adrenalin levels may reduce amphetamine removal from the body based on these in vitro studies. Also, the use of stomach acid lowering drugs could result in more rapid systemic uptake of these amphetamine derivatives.

Key Words: MDMA, MDEA, p-MA, epinephrine, noradrenalin, reserpine 



\section{Introduction}

The amphetamine family of compounds include drugs such as dexamphetamine (Dex), pseudoephedrine and “ecstasy” (3,4-methylenedioxymethamphetamine (MDMA) and its derivatives; methylenedioxyethylamphetamine (MDEA) \& para-methoxyamphetamine (p-MA)). Although dexamphetamine has a legitimate pharmacological role in enhancing dopaminergic and noradrenergic neural responses in attention deficient hyperactivity disorder (ADHD), abuse of this drug along with the illicit drug MDMA, appear to be gaining momentum in western communities. Some reports have found high interindividual variability in response to Dex, when used for ADHD and variability in toxicity to recreational MDMA use has also been noted in recent studies (Han and Gu, 2006; Soares et al., 2004; Zhu et al., 2006), suggesting the possible involvement of metabolic or transport factors that may be saturable, contributing to varied toxicities. In addition, some studies have suggested that MDMA and its derivatives may be substrates for the efflux transporter, Pglycoprotein, and that this may contribute to variability of adverse effects (Ketabi-Kiyanvash et al., 2003; Mann et al., 1997), while recent studies question its involvement (Bertelsen et al., 2006; Upreti and Eddington, 2008)

In this study we used bi-directional transport studies to confirm the non-involvement of Pglycoprotein in the pharmacokinetics of these amphetamines, and to examine inhibition of the recently discovered pH gradient efflux phenomenon (Kuwayama et al., 2008) with these compounds and have examined, through inhibition studies, what transport mechanisms could be responsible for the significant efflux observed in our study. The highly P-glycoprotein expressing Caco-2 sub clone, CLEFF-9, coupled with fluorescent HPLC protocols for the amphetamine detection were used.

\section{Materials and Methods.}




\subsection{Chemicals.}

MDMA, MDEA, p-MA, Amiloride, 5-(N-ethyl-N-isopropyl) amiloride (EIPA), adrenalin (epinephrine), noradrenalin (norepinephrine), sodium azide, sodium orthovanadate, Carbonyl cyanide 3-chlorophenylhydrazone (FCCP), nifedipine, L-DOPA, calmidazolium chloride, dibutyryl cAMP, tetra-ethylammonium, pheniramine hydrochloride and reserpine were supplied by Sigma Aldrich (Castle Hill, NSW, Australia). Dexamphetamine was supplied by Sigma pharmaceuticals (Croydon, Victoria, Australia). PSC-833 (valspodar - a cyclosporine derivative) was kindly donated by Novartis Pharmaceuticals (Basel, Switzerland), while GF120918 (an acridonecarboxamide) was kindly donated by Glaxo-SmithKline (Boronia, Vic, Australia). (-)Pseudoephedrine was kindly donated by Prof. John Parkin from the School of Pharmacy, Curtin University. MK571 and diltiazem hydrochloride were purchased from BIOMOL international (Plymouth meeting, Philadelphia, USA). All other materials were of analytical grade.

\subsection{Cell Transport studies.}

Drug transport was studied in an in vitro gastrointestinal model using a monolayer of a CLEFF9 subclone of human Caco-2 cells with high P-glycoprotein-mediated efflux (Crowe et al., 2006; Crowe and Teoh, 2006) and previously-reported experimental protocols (Crowe and Lemaire, 1998; Crowe and Teoh, 2006; Crowe and Wong, 2004). Briefly, CLEFF-9 cells were seeded onto Millicell polycarbonate $0.6 \mathrm{~cm}^{2}$ filter inserts in 24 well plates at 65,000 cells/ $\mathrm{cm}^{2}$. Cells were grown in high glucose Dulbecco’s modified eagle medium (DMEM) with 25 mM Hepes (pH 7.4), 2 mM glutamine, $1 \mathrm{mM}$ non-essential amino acids, $100 \mathrm{U} / \mathrm{ml}$ penicillin-streptomycin and $10 \%$ foetal calf serum) in a $37^{\circ} \mathrm{C}$ incubator with $5 \% \mathrm{CO}_{2}$.

Cells were incubated for 21-25 days to allow full maturation of the monolayer of cells (Hosoya et al., 1996). The TEER was measured both before and immediately after the study using 
an EVOM meter and the ENDOHM 12 chamber (World Precision Instruments, Sarasota, FL, USA) with readings between $500-900 \Omega . \mathrm{cm}^{2}$ for all cells in this study.

Transport studies were conducted using hanks balanced salts solution (HBSS) supplemented with both glucose and HEPES to give final concentrations of 25 and $10 \mathrm{mM}$ respectively. For $\mathrm{pH}$ 6.0 studies, 10 mM 2-Morpholinoethanesulfonic acid (MES) (USB, Cleveland, Ohio, USA) was used instead of HEPES.

\subsection{P-glycoprotein and other transporter inhibition:}

In studies where inhibition of P-glycoprotein or a multitude of other transporters were performed in conjunction with known inhibitors, cells were pre-incubated in buffer containing the inhibitors for 30 min. The P-glycoprotein inhibitors included $4 \mu \mathrm{M}$ PSC-833 and $4 \mu \mathrm{M}$ GF120918. The general MRP inhibitors $500 \mu \mathrm{M}$ probenecid or $25 \mu \mathrm{M}$ MK571 were also used, to provide comparative non-P-glycoprotein efflux inhibition data, depending on which agent gave the least interference in our HPLC assays. Other transport inhibitiors included the proton ionophore, FCCP (Carbonyl cyanide 4-(trifluoromethoxy)phenylhydrazone $(40 \mu \mathrm{M}), 100 \mu \mathrm{M}$ adrenalin and noradrenalin, $250 \mu \mathrm{M}$ L-DOPA and $500 \mu \mathrm{M}$ tetra-ethylammonium (TEA) for testing OCT1-3 and hEMT sensitivity and the $\mathrm{Na}^{+} / \mathrm{H}^{+}$antiport inhibitors amiloride $(1 \mathrm{mM})$ and EIPA (5-(N-Ethyl-NIsopropyl) amiloride $(100 \mu \mathrm{M})$ were also used. Energy metabolism inhibitors Na-Azide (1mM) combined with $50 \mathrm{mM}$ 2-deoxyglucose and sodium-orthovanadate $(100 \mu \mathrm{M})$ were used as was 400 $\mu \mathrm{M}$ dibutyryl cAMP to induce cAMP mediated protein kinase activity while $500 \mu \mathrm{M}$ theophylline was also used to increase intracellular cAMP levels. $75 \mu \mathrm{M}$ calmidazolium was used to block $\mathrm{Ca}^{2+} /$ calmodulin signalling pathways. $100 \mu \mathrm{M}$ diltiazem, and $100 \mu \mathrm{M}$ nifedipine were used as $\mathrm{Ca}^{2+}$ channel blockers, while $200 \mu \mathrm{M}$ paraquat inhibits novel transporters related to, but distinct from the dopamine transporter. $100 \mu \mathrm{M}$ reserpine was used to block vesicular monoamine uptake. $1 \mathrm{mM}$ 
Thiamine-HCl (Vitamin B1) was used as another organic cation thought to have competitive blocking ability at various transporter sites and $200 \mathrm{uM}$ pheniramine was used to block $\mathrm{H}_{1}$ receptors. During the transport study these modifying agents were also present in the donor chamber with our test compounds and in the receiver chamber, at the same concentrations as stated above.

\subsection{Amphetamine derivatisation.}

As dexamphetamine and pseudoephedrine do not have inherent fluorescent characteristics, and their UV spectra are also very weak, these two amphetamines required derivatisation with dansyl chloride [(5-dimethylamino)naphthalene-1-sulfonyl chloride] using established protocols (Wang and Fuh, 1996; Yamada et al., 2002). After completion of all collections, aqueous samples were increased to $\mathrm{pH} 9$ with carbonate buffer and incubated in a total of $50 \%$ acetone containing the dansyl chloride for $44^{\circ} \mathrm{C}$ for 1 hour. Aliquots were able to be added directly to the HPLC system without extraction and provided very linear std curves with an $r^{2}$ of 0.9995 between 0.1 and $100 \mu \mathrm{M}$ concentrations for both derivatised amphetamines tested measuring fluorescence at 345nm excitation and 500nm emission.

MDMA, MDEA and p-MA displayed inherent fluorescent spectra with excitation at 280nm and emission at 333nm. The signal strength for p-MA was not as strong as either MDMA nor MDEA, thus we were restricted to $250 \mathrm{nM}$ detection limits in our system for p-MA, yet could detect down to $25 \mathrm{nM}$ MDMA and MDEA allowing lower concentrations to be used with these 2 latter amphetamine derivatives.

\subsection{HPLC analysis.}

The mobile phase for detection of MDMA, MDEA and p-MA consisted of $20 \mathrm{mM} \mathrm{NaH} \mathrm{PO}_{4}$ [BDH-Merck, Kilsyth, Victoria] pH 3.8: acetonitrile [EM Science, Gibbstown, NJ, USA] (83:17 
v/v). The Agilent 1100 series HPLC system ran at $1.2 \mathrm{~mL} / \mathrm{min}$ with 25uL of MDMA, MDEA or pMA added to a Zorbax stable-bonded AQ column, $5 \mu \mathrm{m}$ pores, $15 \mathrm{~cm}$ x $4.6 \mathrm{~mm}$ I.D. with mated guard column [Agilent, NSW, Australia]. Typical retention times for p-MA, MDMA and MDEA were 3.1, 3.6 and 4.5 minutes respectively.

Modifications to this protocol for dansyl-chloride derivatised dexamphetamine and pseudoephedrine included changing the mobile phase to water:acetonitrile (35:65) and the column was changed to an Alltech Alltima High-Performance $\mathrm{C}_{18}$ HL column with 3um pores, $15 \mathrm{~cm}$ x 4.6 mm I.D. Typical retention times for pseudoephedrine and dexamphetamine were 7.0 and $7.5 \mathrm{~min}$ respectively. Ephedrine was used as our internal std. This eluted at $5.5 \mathrm{~min}$ in this system.

\subsection{Data analysis.}

Drug transport through cell monolayers was calculated both as a simple amount passing the monolayer per min, which would vary depending on the concentration used in the donor compartment, and as an apparent permeability co-efficient as calculated previously (Crowe and Lemaire, 1998). Briefly, this calculation allows for a modification to the original Artursson equation (Artursson, 1990), where the concentration in the donor compartment $\left(\mathrm{C}_{0}\right)$ is re-calculated after every 30 min time point to compensate for that already present in the receiver chamber to ensure a greater accuracy in calculating the rate of movement into the opposing chamber (Youdim et al., 2003).

Results in this study are presented as the mean \pm S.E.M., standardised on individual protein concentrations. Significant differences between values were examined using Student's two-tailed unpaired t-test or one way ANOVA. Results were considered significant if $\mathrm{P}<0.05$.

\section{Results}


None of the amphetamines were shown to be substrates for the efflux transporter, Pglycoprotein. At pH 7.4 only equivalent transport in both directions for all amphetamine derivatives was observed (Table 1, Fig. 1). When P-glycoprotein inhibitors were added the same transport rates were still observed (Fig. 1, Table 1) in both directions. Transport rates above $25 \times 10^{-6} \mathrm{~cm} / \mathrm{sec}$ are considered indicative of either $100 \%$ gastrointestinal absorption or very rapid organ uptake for drugs already in the systemic circulation. As Dex, pseudoephedrine, MDMA, MDEA and p-MA all showed very rapid ( $>27 \times 10^{-6} \mathrm{~cm} / \mathrm{sec}$ flux) at $\mathrm{pH} 7.4$ in any direction (Table 1$)$, transport through organ systems for these drugs will be very rapid. However, using a $\mathrm{pH}$ 6.0/7.4 gradient, which is indicative of gastrointestinal absorption through-out the small intestine, due to active $\mathrm{Na}^{+}-\mathrm{H}^{+}$pumps generating acidic microclimates at the microvilli aqueous boundary layers in the intestinal tract (Tsuji and Tamai, 1996), we find the apical to basolateral rate of transport for dexamphetamine was approximately $10 \times 10^{-6} \mathrm{~cm} / \mathrm{s}$ (Table 1 ), yet the basolateral to apical rate of transport was 16 fold higher resulting in considerable efflux. Similarly, MDMA pH gradient studies showed an efflux of 13 fold under these conditions (Fig. 2, Table 2). Dexamphetamine showed no reversal in the presence of the P-glycoprotein inhibitor, PSC-833 (Table 2). This was to be expected, as we have shown previously that P-glycoprotein is not influenced by pH gradients, such that efflux systems at pH 6/7.4 that are absent at pH 7.4/7.4 are unlikely to be P-glycoprotein mediated (Crowe and Wong, 2004). Sodium Azide and FCCP were able to reduce efflux by 2 to 3 fold for MDMA, MDEA and p-MA (4 fold in the case of Azide on MDMA efflux) (Tables 2 and 3), implying that an unknown active transport system linked to the antiport movement of $\mathrm{H}^{+}$ions was involved (in part) for $\mathrm{pH}$ dependent efflux. There was very little metabolism $(<1 \%)$ of amphetamines evident from our fluorescence-HPLC detection (results not shown), and this was not enough to suggest intracellular metabolism was responsible, rather than transport.

Amiloride at a $1 \mathrm{mM}$ concentration and its more potent analogue EIPA (used at $100 \mu \mathrm{M}$ ) were added separately to determine any influence of $\mathrm{Na}^{+} / \mathrm{H}^{+}$antiporters on amphetamine transport. 
Although amiloride did result in some reduction of drug efflux, the 200x more potent, and selective, analogue did not, suggesting amiloride may be acting on one of the many other protein or sodium mediated transporters that it has some affinity towards (Tables 2 and 3).

It is well known that amphetamines can inhibit neuronal uptake of adrenalin and noradrenalin (Silvestrini et al., 1991). Thus, could the reverse also occur, with catecholamines reducing pH dependent amphetamine transport? Certainly our results showed adrenalin reducing MDMA transport two fold (Table 2), while MDEA was affected by both adrenalin and noradrenalin, and p-MA was only affected by noradrenalin (Table 3), suggesting $\mathrm{pH}$ dependent specific catecholamine transporters in the intestine may excrete amphetamine derivatives back to the intestinal lumen, reducing uptake. This varied responses to both adrenalin and noradrenalin though, suggests a group of similar transporters are involved across the amphetamine derivatives, rather than one subtype.

With the variable effects of adrenalin and nor-adrenalin, it was considered that the human organic cation transporters (OCT) may be playing a role in amphetamine transport, which resulted in the OCT 1, 2 and 3 inhibitor tetraethylammonium (TEA) being examined (Schomig et al., 2006). However, in our study TEA did not decrease efflux, and instead may have increased amphetamine efflux to 40-50\% higher levels than the $\mathrm{pH}$ gradient alone (Table 2 and 3). A recent article examining uptake of MDMA at pH 6 into Caco-2 cells also did not show any influence of TEA, yet they did show that a $\mathrm{H}_{1}$ receptor blocker could reduce uptake by one third (Kuwayama et al., 2008). Thus, we used the $\mathrm{H}_{1}$ receptor blocker, pheniramine, on bidirectional transport yet could find no influence of this drug on MDMA and MDEA. However, for p-MA where Ap to Bas transport was significantly elevated, without any effect on Bas to Ap transport, this reduced the efflux ratio to less than 5, which was the most significant efflux ratio reduction for all drugs examined with p-MA (Table 3). 


\section{Discussion:}

Initially our studies focussed on P-glycoprotein mediated efflux of amphetamine as an extension from earlier reports that indirectly suggested P-glycoprotein to have some involvement in the transport of these amphetamine derivatives, especially MDMA (Ketabi-Kiyanvash et al., 2003; Mann et al., 1997). However, we were not able to find any evidence of P-glycoprotein mediated efflux for any of the amphetamine derivatives tested. Two recent publications from other laboratories examining methamphetamine and MDMA have likewise shown no P-glycoprotein mediated efflux (Bertelsen et al., 2006; Upreti and Eddington, 2008), in keeping with our own finding for these drugs as well as unreported until now evidence that p-MA, MDEA, dexamphetamine and pseudoephedrine as shown here, are also not P-glycoprotein substrates.

It has been well characterised that kidney excretion of pseudoephedrine and other ephedrine derived decongestant drugs are dependant on urinary $\mathrm{pH}$. The higher the tubular filtrate $\mathrm{pH}$, the less ephedrine based drug is released to the urine (Kanfer et al., 1993; Till and Benet, 1979). Previous work from our laboratory showed Caco-2 cells to have proton coupled antiporter transport coupled to loperamide (Crowe and Wong, 2004), so we were keen to examine whether Caco-2 cells were able to show $\mathrm{pH}$ mediated changes in transport of amphetamine derivatives either in the uptake or efflux directions. It became evident that all amphetamine derivatives were transported in the efflux direction when presented with physiological $\mathrm{pH}$ values of 6 on the luminal side equivalent (apical side) and 7.4 on the blood side equivalent (basolateral side) in our studies. Ionic changes alone could feasibly account for profound changes in directional transport through cell membranes if their pKa's were close to one of the $\mathrm{pH}$ values used in our study. However, these amphetamines have pKa values from 9.9 to 10.1 (Kuwayama et al., 2008), suggesting that at all times at least $99.6 \%$ of drugs are ionised. To further illustrate the likelihood of transporter activation, reverse $\mathrm{pH}$ gradient studies, although not physiologically relevant, were conducted to prove that the same significant 13 fold $\mathrm{pH}$ gradient changes would not occur if the gradients were reversed, thereby confirming the 
evidence of efflux transporters and not limiting the data to properties of the amphetamines alone. Our data here confirmed that although a small reverse gradient was achieved, it was only in the order of 2.5 fold, not 13 fold as shown with the physiological situation.

As Caco-2 cells have been shown to express many of the enzyme and transport systems of the human gastrointestinal tract (except cytochrome P450 systems) (Gan and Thakker, 1997; Hidalgo et al., 1989), we examined a range of potential transporter inhibition methods to attempt to elucidate the mechanisms responsible for this $\mathrm{pH}$ dependent efflux. Interestingly, a very recent publication has also shown this pH gradient efflux of MDMA in Caco-2 cells (Kuwayama et al., 2008). In our accumulation studies for MDMA and its derivatives and were unable to show any increase in accumulation between 3 and 60 min of exposure. Their publication confirms this, as they showed that by 3 min, cellular uptake is almost saturated (Kuwayama et al., 2008). This is different to transcellular transport where our studies showed linear transport rates through our Caco2 subclone cells for at least 120 min (Fig. 2).

The first line of evidence for carrier mediated transport action of amphetamine derivatives in a 1.4pH gradient environment came from the use of energy metabolism inhibitors such as sodiumazide. This significantly reduced the efflux ratio in our studies. Additionally, the ATP binding cassette inhibitor sodium-orthovanadate was also able to cause similar inhibition, suggesting a carrier protein that directly uses ATP was responsible. Further studies showed that this transport is linked to the broad cAMP protein kinase messenger system within cells, as dibutyryl cAMP was able to reduce efflux, suggesting that this transporter can be down regulated by elevating cAMP levels.

Amiloride is a potent inhibitor of the intestinal $\mathrm{Na}^{+} / \mathrm{H}^{+}$antiporter present in the small intestine. Although some inhibition of methamphetamine derivative efflux was shown in our study, amiloride does also affect a number of other ion channels. Thus, to confirm the use of $\mathrm{Na}^{+} / \mathrm{H}^{+}$ antiport mechanisms in the efflux of our amphetamine derivatives we used the 200 times more 
potent amiloride analogue, EIPA, which surprisingly showed no significant reduction on the amphetamine efflux, indicating that the $\mathrm{Na}^{+} / \mathrm{H}^{+}$channels were not used.

Caco-2 cells have been shown previously to express $\mathrm{H}^{+}$coupled monocarboxylic acid transport systems, and peptide delivery systems that could be inhibited with the proton ionophore FCCP (Bailey et al., 1996; Wu et al., 2000). This study showed efflux transport of MDMA, MDEA and p-MA could be reduced when co-incubated with this proton ionophore. It is not likely to be the $\mathrm{H}^{+}$coupled monocarboxylic acid transport nor tertiary di/tri peptide transporters (Bailey et al., 1996; Wu et al., 2000), as the direction of transport is to remove the amphetamine derivatives, not for increased absorption under these physiological $\mathrm{pH}$ gradient conditions. In addition, recent publications have highlighted other $\mathrm{H}^{+}$mediated transporters represented on Caco-2 cells, such as a sodium independent L-type amino acid transport system that is responsible for oral uptake of LDOPA (Fraga et al., 2002). However, when using L-DOPA at high concentrations to competitively inhibit this transport system, we were unable to show any significant influence on methamphetamine derivative efflux from our system. In fact, for MDEA and p-MA the presence of additional L-DOPA on both sides of the membrane appeared to accelerate the efflux mechanism back to the apical chambers, although there was no significant addition efflux on MDMA.

In an attempt to narrow the identification of this transporter family further, we noted that Caco-2 cells show voltage gated depolarisation via adrenalin and noradrenalin even though they are devoid of $\alpha$ or $\beta$ adrenoreceptors (Grasset et al., 1985). Recent studies showed Caco-2 cells to express the human extraneuronal monamine transporter (hEMT)(Calhau et al., 2003), as well as the closely related organic cation transporters OCT1 and OCT3, which are known systemic transporters of both adrenalin and noradrenalin (Calhau et al., 2003; Friedgen et al., 1996; Monteiro et al., 2005), and has been shown to have mRNA expression similar to the human small intestine (Seithel et al., 2006). hEMT is considered the main route of catecholamine transport within extraneuronal sites though (Schomig et al., 2006). The potential use of either hEMT, OCT1, 2 or 3, could have explained why MDMA efflux was inhibited by adrenalin, yet not noradrenalin, especially given that 
in reciprocal roles, one report claimed MDMA and dexamphetamine could prevent catecholamine transport though OCTs (Amphoux et al., 2006). Efflux of MDEA was inhibited by both adrenalin and noradrenalin, and p-MA had its efflux partially mediated by noradrenalin and surprisingly pheniramine (a histamine $\mathrm{H}_{1}$ blocker), which could indicate a broader spread of these analogues in their $\mathrm{pH}$ dependent efflux across multiple transporters. It is possible that other as yet uncharacterised transporters are utilised, however, by a process of elimination, the hEMT transporter appeared the most likely candidate given the lack of efflux inhibition by tetraethylammonium, which affects OCT1 through 3 but does not appear to affect hEMT (Schomig et al., 2006). Kuwayama also found that as tetraethylammonium did not reduce MDMA uptake into their Caco-2 cultures they excluded these transporters as significant in intracellular absorption of amphetamines (Kuwayama et al., 2008).

Finally, we used the $\mathrm{Ca}^{2+}$ channel blocker, nifedpine, which had no effect on amphetamine efflux, and also the L-DOPA inhibiting $\mathrm{Ca}^{2+} /$ calmodulin inhibitor calmidazolium (Fraga et al., 2002), but this also had no effect, suggesting no direct involvement of the extraneuronal dopamine transporter, even though L-DOPA increased efflux in this current study. Lastly we examined reserpine, which is normally considered a vesicular monoamine transport (VMAT) inhibitor, blocking catecholamine uptake into adrenergic neurons (Schwab and Thoenen, 1983). Caco-2 cells are not known to possess vesicular uptake mechanisms, and certainly the rapid low uptake equilibrium results from our own group and Kuwayama’s (Kuwayama et al., 2008) would suggest that no such vesicular accumulation system exists, yet reserpine, was effective at reducing the extent of MDMA, MDEA and p-MA efflux in our cloned Caco-2 cell line. Interestingly, VMAT does secrete protons (Blackmore et al., 2001) and other studies have reported that reserpine, by blocking VMAT, encourages the secretion of neurotransmitters because there are no longer able to be stored (Partilla et al., 2006). In addition, it has been shown that all of the amphetamine derivatives are substrates for this same vesicular system and can deplete endogenous bioamines in the vesicles by reducing the $\mathrm{pH}$ gradient within them (Sulzer and Rayport, 1990). Caco-2 cells have 
not been shown to exhibit this exact system, but the principles of amphetamine derivatives being effluxed back to the luminal side does appear linked to their neuronal mechanism of action. From the body’s perspective though, these in vitro results suggest that under extreme stress when high adrenalin concentrations are circulating, or when $\mathrm{H}_{2}$ receptor blockers, proton pump inhibitors or antacids are consumed, co administration of amphetamine derivates, be they for ADHD or for illicit use, could present into the systemic circulation at significantly higher concentrations because of these stress induced conditions or acid lowering drug co-administration, which could have severe adverse health effects. 


\section{Dexamphetamine}
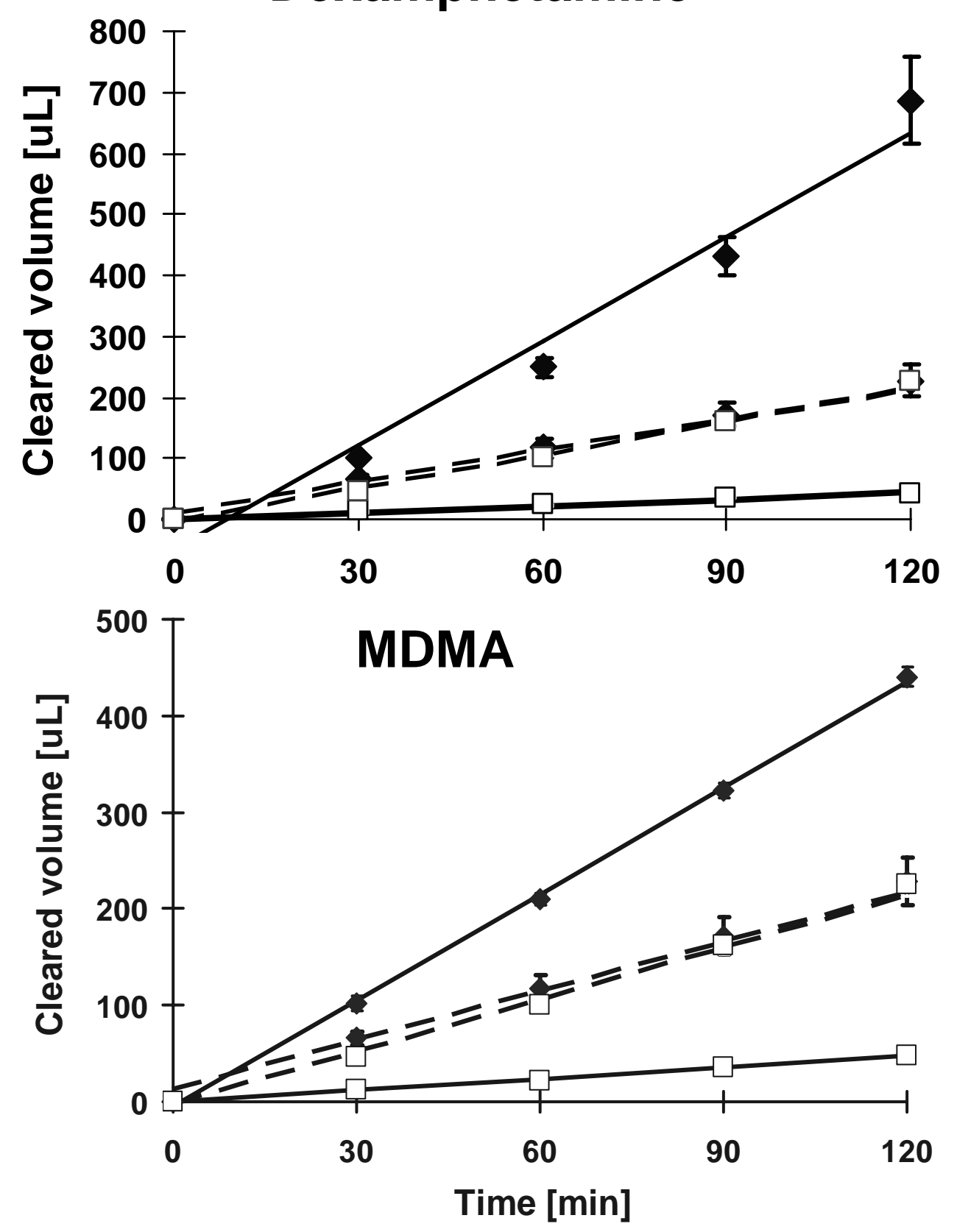

MDEA

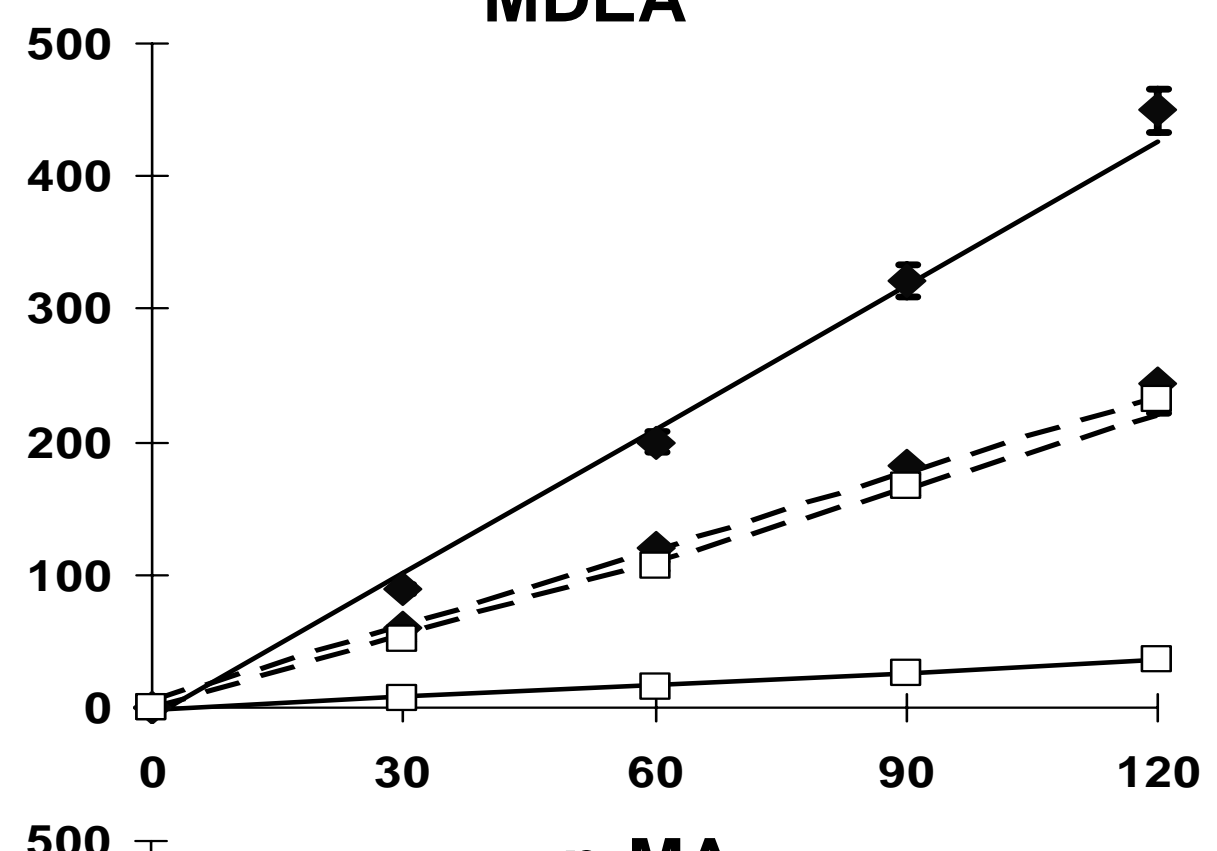

p-MA

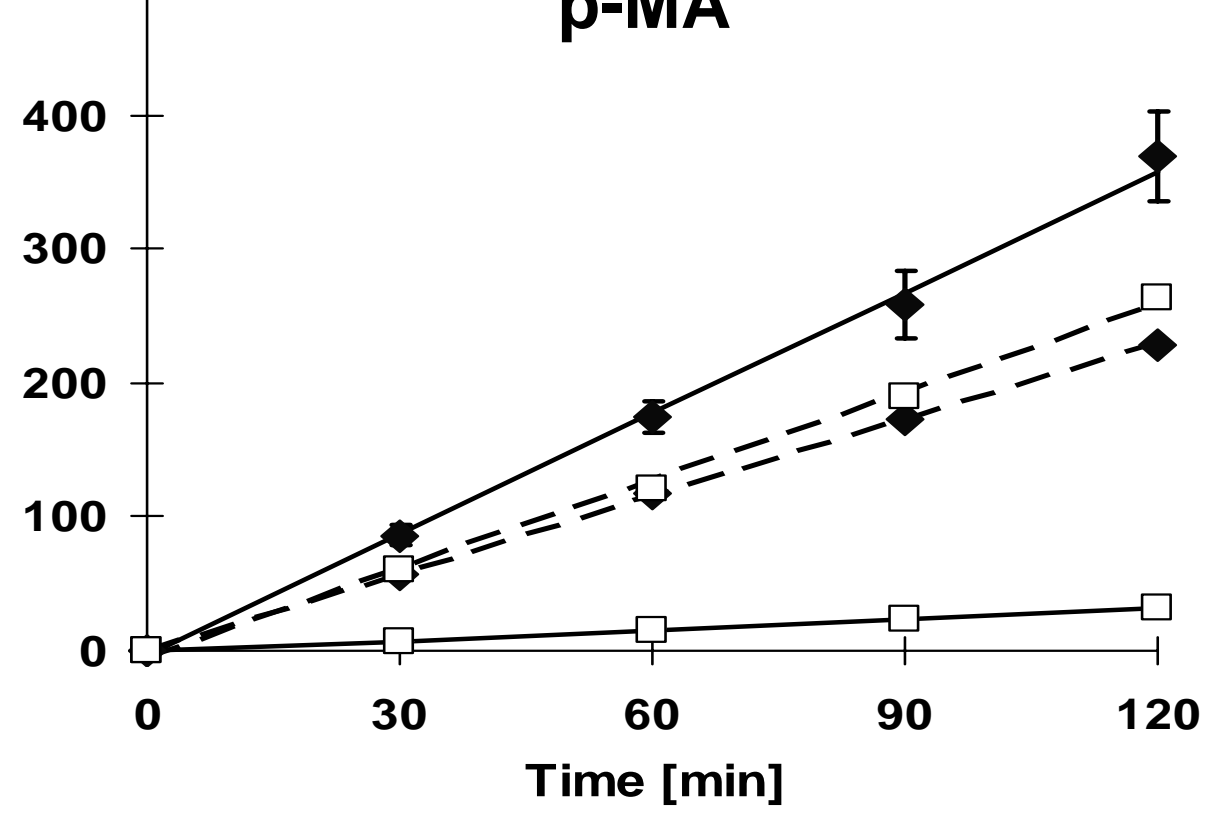



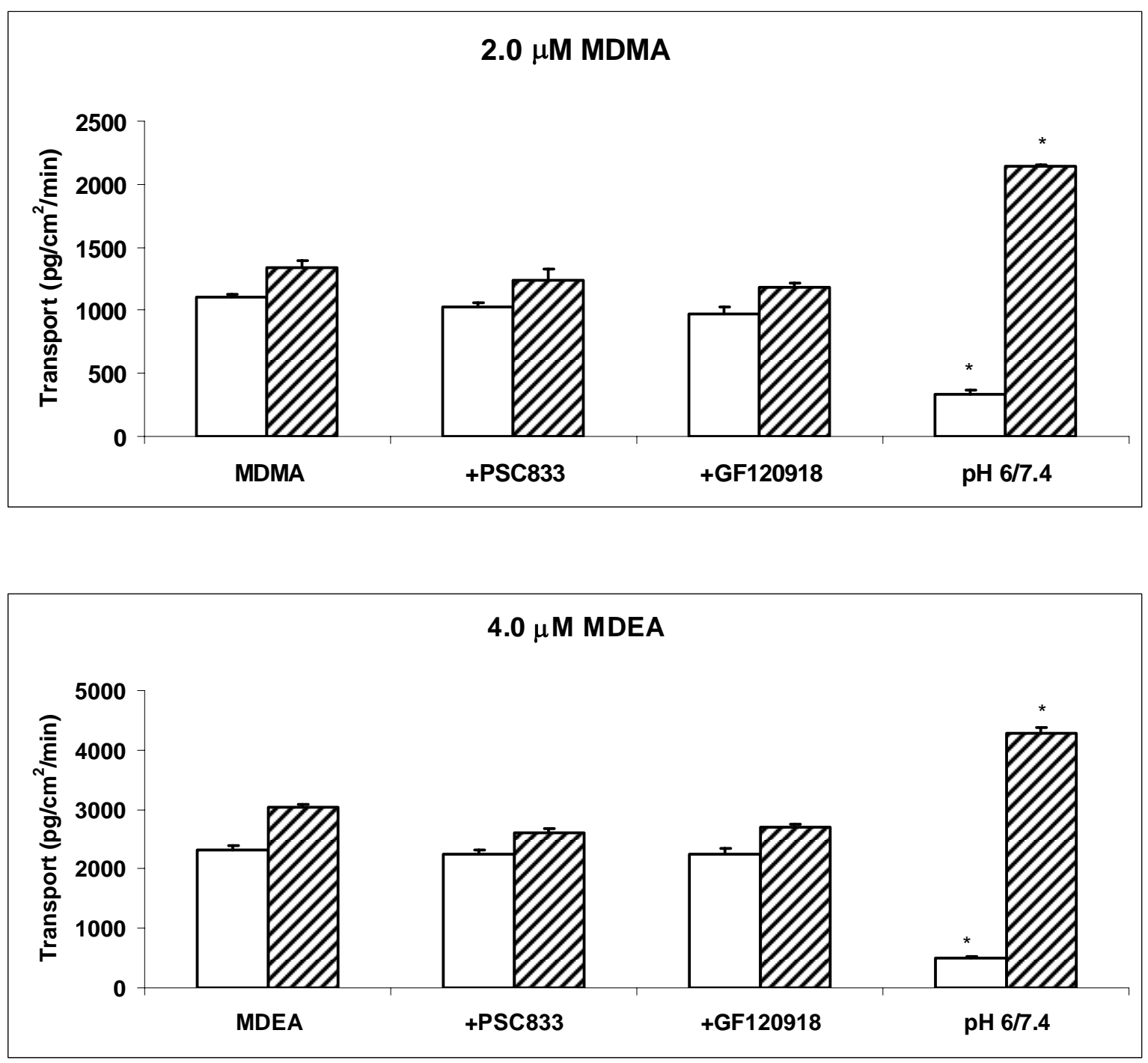
Table 1 :

Permeability rates for dexamphetamine sulphate, pseudoephedrine, MDMA \& MDEA with or without the potent P-glycoprotein inhibitor; PSC-833, through Caco-2 (CLEFF9) cell monolayers in both apical to basolateral and basolateral to apical directions at pH 7.4. Ratios shown here are in the net apical to basolateral flow direction. Data indicates the mean \pm S.E.M. of triplicates.

$\begin{array}{cr}\text { Papp A-B } & \text { Papp B-A } \\ \left(\times 10^{-6} \mathrm{~cm} / \mathrm{s}\right) & \left(\times 10^{-6} \mathrm{~cm} / \mathrm{s}\right)\end{array}$

Dexamphetamine Sulphate

$20 \mu \mathrm{M}$

$20 \mu \mathrm{M}+4 \mu \mathrm{M}$ PSC-833

(-) Pseudoephedrine

$20 \mu \mathrm{M}$

$20 \mu \mathrm{M}+4 \mu \mathrm{M}$ PSC-833

MDMA

$20 \mu \mathrm{M}$

$20 \mu \mathrm{M}+4 \mu \mathrm{M}$ PSC-833

$2 \mu \mathrm{M}$

$2 \mu \mathrm{M}+4 \mu \mathrm{M}$ PSC-833

MDEA

$4 \mu \mathrm{M}$

$4 \mu \mathrm{M}+4 \mu \mathrm{M}$ PSC-833

p-MA

$5 \mu \mathrm{M}$

$5 \mu \mathrm{M}+4 \mu \mathrm{M}$ PSC-833
$34.4 \pm 4.3$

$27.8 \pm 4.0$

$46.9 \pm 1.8$

$42.6 \pm 7.3$

$55.64 \pm 3.2$

$49.66 \pm 3.8$

$51.2 \pm 2.1$

$46.4 \pm 2.7$

$60.7 \pm 0.8$

NA
$28.5 \pm 1.1$

$22.7 \pm 0.9$

A-B direction

$36.2 \pm 3.9^{a}$

1.1

1.1

$45.24 \pm 7.4$

1.1

NA 
$\mathrm{a}=$ Significant difference in transport direction $(\mathrm{P}<0.05)$.

$\mathrm{b}=$ Significance of an inhibitor action for a given transport direction $(\mathrm{P}<0.05)$ 
Table 2 :

Permeability rates for dexamphetamine sulphate and MDMA with or without numerous transporter inhibitors through Caco-2 (CLEFF9) cell monolayers in both apical to basolateral and basolateral to apical directions at $\mathrm{pH} 7.4$ in both wells and gradient $\mathrm{pH}$ studies with $\mathrm{pH} 6.0$ medium in the upper chambers and $\mathrm{pH} 7.4$ medium in the lower. Comparative reverse $\mathrm{pH}$ studies are also included with pH 7.4 in apical chambers and ph 6.0 medium in basolateral chambers to illustrate directional transport not only related to diffusional characteristics in $\mathrm{pH}$ gradient conditions. Ratios shown here are in the net basolateral to apical flow direction. Data indicates the mean \pm S.E.M. of triplicates.

Papp A-B

$\mathrm{pH}$ apical / basolateral

\section{Dexamphetamine Sulphate}

$4 \mu \mathrm{M} \mathrm{pH} 7.4 / 7.4$

$4 \mu \mathrm{M} \mathrm{pH} 6.0 / 7.4$

$4 \mu \mathrm{M}$ pH 6.0/7.4+PSC833

$4 \mu \mathrm{M} \mathrm{pH} \mathrm{6.0/7.4+FCCP}$

\section{MDMA}

$0.5 \mu \mathrm{M}$ pH 7.4/7.4

$0.5 \mu \mathrm{M} \mathrm{pH}$ 7.4/7.4+vanadate

$0.5 \mu \mathrm{M}$ pH 6.0/7.4

0.5 $\mu \mathrm{M}$ pH 6.0/7.4+azide

0.5 $\mu \mathrm{M} \mathrm{pH} \mathrm{6.0/7.4+vanadate}$

$0.5 \mu \mathrm{M} \mathrm{pH} 6.0 / 7.4+\mathrm{FCCP}$

0.5 $\mu \mathrm{M} \mathrm{pH} \mathrm{6.0/7.4+noradrenalin}$

0.5 $\mu \mathrm{M}$ pH 6.0/7.4+adrenalin $\left(\times 10^{-6} \mathrm{~cm} / \mathrm{s}\right)$

$51.1 \pm 3.0$

$9.7 \pm 0.5$

$7.2 \pm 0.4^{\mathrm{a}}$

$8.6 \pm 0.5$

$51.5 \pm 1.1$

$56.2 \pm 1.9$

$7.3 \pm 0.7$

$14.5 \pm 0.8^{\mathrm{a}}$

$13.6 \pm 0.4^{\mathrm{a}}$

$12.6 \pm 0.4^{\mathrm{a}}$

$10.2 \pm 0.4^{\mathrm{a}}$

$9.3 \pm 0.8$
Papp B-A

$\left(\times 10^{-6} \mathrm{~cm} / \mathrm{s}\right)$

(Efflux)

B-A direction

$43.2 \pm 2.6$

$157.7 \pm 15.8^{\mathrm{a}}$

$101.7 \pm 34.7^{\mathrm{a}}$

$88.5 \pm 8.0^{\mathrm{a}}$

$10.3^{b}$

1.2

16.3

14.1
0.9

0.8

13.0

$84.3 \pm 1.9 \quad \mathbf{5 . 8}^{\mathbf{b}}$

$80.3 \pm 2.5^{a}$

$5.9^{b}$

$71.2 \pm 2.3^{\mathrm{a}}$

$5.6^{b}$

12.0

$122.3 \pm 7.0^{\mathrm{a}}$

$66.7 \pm 2.0^{a}$

$7.2^{b}$ 


$\begin{array}{lccc}0.5 \mu \mathrm{M} \text { pH 6.0/7.4+paraquat } & 7.4 \pm 0.5 & 108.3 \pm 2.3 & \mathbf{1 4 . 6} \\ 0.5 \mu \mathrm{M} \text { pH 6.0/7.4+Thiamine } & 12.7 \pm 0.1^{\mathrm{a}} & 101.8 \pm 2.2 & \mathbf{8 . 0}^{\mathbf{b}} \\ 0.5 \mu \mathrm{MpH6} .0 / 7.4+\text { dibutyryl cAMP } & 12.5 \pm 0.7^{\mathrm{a}} & 82.3 \pm 1.7 & \mathbf{6 . 6}^{\mathbf{b}} \\ 0.5 \mu \mathrm{M} \text { pH 6.0/7.4+L-DOPA } & 8.5 \pm 0.6 & 99.7 \pm 2.2 & \mathbf{1 1 . 8} \\ 0.5 \mu \mathrm{M} \text { pH 6.0/7.4+TEA } & 9.0 \pm 0.1^{\mathrm{a}} & 153.8 \pm 0.9^{\mathrm{a}} & \mathbf{1 7 . 0}^{\mathbf{b}} \\ 0.5 \mu \mathrm{M} \text { pH 6.0/7.4+pheniramine } & 7.5 \pm 0.4 & 97.3 \pm 2.8 & \mathbf{1 2 . 9} \\ 0.5 \mu \mathrm{M} \text { pH 6.0/7.4+reserpine } & 10.7 \pm 0.6^{\mathrm{a}} & 65.1 \pm 3.9^{\mathrm{a}} & \mathbf{6 . 1} \\ 0.5 \mu \mathrm{M} \text { pH 7.4/6.0 } & 51.9 \pm 1.2 & 21.3 \pm 0.2 & \mathbf{0 . 4} \\ 0.5 \mu \mathrm{M} \text { pH 7.4/6.0+reserpine } & 49.2 \pm 3.1 & 17.4 \pm 0.6 & \mathbf{0 . 4}\end{array}$

Concentration of each inhibitor used is listed as follows; $40 \mu \mathrm{M}$ FCCP (Carbonyl cyanide 4(trifluoromethoxy)phenylhydrazone, $100 \mu \mathrm{M}$ adrenalin, 1mM amiloride, 1mM Na-Azide combined with prior addition of $50 \mathrm{mM}$ 2-deoxyglucose, $400 \mu \mathrm{M}$ dibutyryl cAMP, $250 \mu \mathrm{M}$ L-DOPA, 100 $\mu \mathrm{M}$ nifedipine, $100 \mu \mathrm{M}$ noradrenalin, $100 \mu \mathrm{M}$ Na-orthovanadate, $200 \mu \mathrm{M}$ paraquat, $200 \mu \mathrm{M}$ pheniramine, $100 \mu \mathrm{M}$ reserpine, $4 \mu \mathrm{M}$ PSC-833, $500 \mu \mathrm{M}$ tetraethylammonium (TEA) and $1 \mathrm{mM}$ Thiamine-HCl (Vitamin B1).

(a) = Significance of an inhibitor action for a given transport direction $(\mathrm{P}<0.05)$

(b) = Significant difference in efflux ratio for inhibitors from $\mathrm{pH}$ gradient 6/7.4 alone 
Table 3 :

Permeability rates for MDEA and p-MA with or without numerous transporter inhibitors through Caco-2 (CLEFF9) cell monolayers in both apical to basolateral and basolateral to apical directions at $\mathrm{pH} 7.4$ in both wells and gradient $\mathrm{pH}$ studies with $\mathrm{pH} 6.0$ medium in the upper chambers and $\mathrm{pH}$ 7.4 medium in the lower. Comparative reverse $\mathrm{pH}$ studies are also included with $\mathrm{pH} 7.4$ in apical chambers and ph 6.0 medium in basolateral chambers to illustrate directional transport not only related to diffusional characteristics in $\mathrm{pH}$ gradient conditions. Ratios shown here are in the net BLAP flow direction. Data indicates the mean \pm S.E.M. of triplicates.

\section{Papp A-B \\ $\left(\times 10^{-6} \mathrm{~cm} / \mathrm{s}\right)$ \\ Papp B-A \\ $\left(\times 10^{-6} \mathrm{~cm} / \mathrm{s}\right)$}

MDEA

$0.5 \mu \mathrm{M} \mathrm{pH} 7.4 / 7.4$

$0.5 \mu \mathrm{M} \mathrm{pH} 6.0 / 7.4$

0.5 $\mu \mathrm{M}$ pH 6.0/7.4+Azide

$0.5 \mu \mathrm{M}$ pH 6.0/7.4+vanadate

0.5 $\mu \mathrm{M}$ pH 6.0/7.4+amiloride

0.5 $\mu \mathrm{M}$ pH 6.0/7.4+calmidazolium

$0.5 \mu \mathrm{M}$ pH 6.0/7.4+EIPA

0.5 $\mu \mathrm{M} \mathrm{pH} \mathrm{6.0/7.4+FCCP}$

0.5 $\mu \mathrm{M} \mathrm{pH} \mathrm{6.0/7.4+noradrenalin}$

$0.5 \mu \mathrm{M} \mathrm{pH}$ 6.0/7.4+adrenalin

0.5 $\mu \mathrm{M}$ pH 6.0/7.4+theophylline

0.5 $\mu \mathrm{M} \mathrm{pH} \mathrm{6.0/7.4+thiamine}$

0.5 $\mathrm{MpH}$ 6.0/7.4+dibutyryl cAMP
$61.3 \pm 3.9$

$10.2 \pm 0.4$

$15.8 \pm 0.7^{\mathrm{a}}$

$10.9 \pm 0.8$

$10.4 \pm 1.4$

$11.6 \pm 0.7$

$7.6 \pm 0.5$

$18.6 \pm 0.6^{\mathrm{a}}$

$11.3 \pm 0.3$

$10.1 \pm 0.7$

$10.7 \pm 1.1$

$10.2 \pm 0.8$

$10.9 \pm 0.7$
Fold difference

(Efflux)

B-A direction

0.8

13.6

$3.4^{b}$

$7.8^{b}$

$9.2^{b}$

$7.8^{b}$

10.5

$5.5^{b}$

$8.2^{b}$

$7.8^{b}$

9.8

10.2

$7.7^{b}$ 
0.5 $\mu \mathrm{M}$ pH 6.0/7.4+L-DOPA

$0.5 \mu \mathrm{MpH} 6.0 / 7.4+\mathrm{TEA}$

$0.5 \mu \mathrm{MpH} 6.0 / 7.4+$ pheniramine

$0.5 \mu \mathrm{M} \mathrm{pH}$ 6.0/7.4+reserpine

$0.5 \mu \mathrm{M} \mathrm{pH} 7.4 / 6.0$

$0.5 \mu \mathrm{M} \mathrm{pH}$ 7.4/6.0+reserpine
$5.2 \pm 0.5^{\mathrm{a}}$

$6.7 \pm 0.8^{\mathrm{a}}$

$9.8 \pm 0.7$

$11.0 \pm 0.3$

$56.0 \pm 3.4$

$73.8 \pm 1.8$
$98.4 \pm 5.2^{a}$

$116.3 \pm 12.2$

$118.3 \pm 7.4$

$85.6 \pm 8.8^{b}$

$23.6 \pm 1.2$

$23.5 \pm 0.2$ $18.8^{b}$

$17.4^{b}$

12.1

$7.8^{b}$

0.4

0.3

\section{p-MA}

$5 \mu \mathrm{M} \mathrm{pH} 7.4 / 7.4$

$60.7 \pm 1.0$

$53.0 \pm 0.5$

0.9

$5 \mu \mathrm{M}$ pH 6.0/7.4

$7.4 \pm 0.5$

$83.4 \pm 8.0$

11.2

$5 \mu \mathrm{M} \mathrm{pH} \mathrm{6.0/7.4+Azide}$

$12.9 \pm 0.6^{\mathrm{a}}$

$72.5 \pm 4.3$

$5.6^{b}$

$5 \mu \mathrm{M}$ pH 6.0/7.4+vanadate

$13.5 \pm 0.5^{\mathrm{a}}$

$92.8 \pm 2.0$

$6.9^{b}$

$5 \mu \mathrm{M}$ pH 6.0/7.4+diltiazem

$8.2 \pm 0.2$

$98.5 \pm 4.6$

12.1

$5 \mu \mathrm{M}$ pH 6.0/7.4+amiloride

$12.2 \pm 0.8^{\mathrm{a}}$

$86.1 \pm 10.4$

$7.1^{b}$

$5 \mu \mathrm{M}$ pH 6.0/7.4+calmidazolium

$9.7 \pm 0.5$

$75.4 \pm 3.7$

$7.8^{b}$

$5 \mu \mathrm{M} \mathrm{pH} \mathrm{6.0/7.4+EIPA}$

$7.8 \pm 1.1$

$125.4 \pm 4.9^{\mathrm{a}}$

16.2

$5 \mu \mathrm{M} \mathrm{pH} \mathrm{6.0/7.4+FCCP}$

$13.5 \pm 0.5^{\mathrm{a}}$

$62.5 \pm 6.8$

$4.6^{b}$

$5 \mu \mathrm{M}$ pH 6.0/7.4+noradrenalin

$10.4 \pm 1.1^{\mathrm{a}}$

$85.6 \pm 9.6$

$8.2^{b}$

$5 \mu \mathrm{M} \mathrm{pH}$ 6.0/7.4+adrenalin

$9.9 \pm 0.1$

$106.0 \pm 2.4$

10.8

$5 \mu \mathrm{M}$ pH 6.0/7.4+paraquat

$6.8 \pm 0.1$

$86.6 \pm 2.6$

12.7

$5 \mu \mathrm{M} \mathrm{pH}$ 6.0/7.4+nifedipine

$8.4 \pm 0.2$

$101.8 \pm 1.0$

12.1

$5 \mu \mathrm{MpH6.0/7.4+dibutryl} \mathrm{cAMP}$

$9.8 \pm 0.6$

$74.3 \pm 4.6$

$7.6^{b}$

$5 \mu \mathrm{M}$ pH 6.0/7.4+L-DOPA

$4.3 \pm 0.2^{\mathrm{a}}$

$84.4 \pm 4.8$

$19.8^{b}$

$5 \mu \mathrm{M} \mathrm{pH} \mathrm{6.0/7.4+TEA}$

$13.7 \pm 1.8^{\mathrm{a}}$

$99.3 \pm 9.1$

$7.2^{b}$

$5 \mu \mathrm{M}$ pH 6.0/7.4+pheniramine

$20.4 \pm 1.9^{\mathrm{a}}$

$96.5 \pm 5.9$

$4.7^{b}$ 
$5 \mu \mathrm{M}$ pH 6.0/7.4+reserpine

$5 \mu \mathrm{M} \mathrm{pH} 7.4 / 6.0$

$5 \mu \mathrm{M} \mathrm{pH} 7.4 / 6.0+$ reserpine

$$
9.8 \pm 0.3
$$

$44.1 \pm 2.8$

$53.8 \pm 1.0$
$76.8 \pm 8.3$

$19.8 \pm 0.9$

$18.6 \pm 0.1$ $7.8^{b}$

0.4

0.3

Concentration of each inhibitor used is listed as follows; $40 \mu \mathrm{M}$ FCCP (Carbonyl cyanide 4(trifluoromethoxy)phenylhydrazone, $100 \mu \mathrm{M}$ adrenalin, $1 \mathrm{mM}$ amiloride, $1 \mathrm{mM}$ Na-Azide combined with prior addition of $50 \mathrm{mM}$ 2-deoxyglucose, $75 \mu \mathrm{M}$ calmidazolium, $400 \mu \mathrm{M}$ dibutyryl cAMP, $100 \mu \mathrm{M}$ diltiazem, $250 \mu \mathrm{M}$ L-DOPA, $100 \mu \mathrm{M}$ EIPA (5-(N-Ethyl-N-Isopropyl) amiloride, $100 \mu \mathrm{M}$ nifedipine, $100 \mu \mathrm{M}$ noradrenalin, $100 \mu \mathrm{M}$ Na-orthovanadate, $200 \mu \mathrm{M}$ paraquat, $200 \mu \mathrm{M}$ pheniramine, $100 \mu \mathrm{M}$ reserpine, $4 \mu \mathrm{M}$ PSC-833, $500 \mu \mathrm{M}$ tetraethylammonium (TEA), $1 \mathrm{mM}$ Thiamine-HCl (Vitamin B1) and $500 \mu \mathrm{M}$ theophylline.

(a) = Significance of an inhibitor action for a given transport direction $(\mathrm{P}<0.05)$

(b) = Significant difference in efflux ratio for inhibitors from $\mathrm{pH}$ gradient 6/7.4 alone 
Figure legend:

Fig. 1.

Rates of apical to basolateral (clear columns) and basolateral to apical transport (striped columns) of 2.0 $\mu \mathrm{M}$ MDMA and 4.0 $\mu \mathrm{M}$ MDEA in CLEFF-9 (Caco-2) monolayers with and without the P-

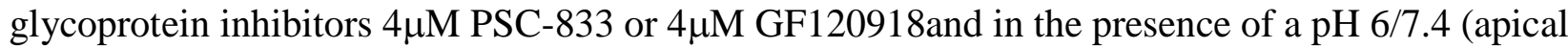
to basolateral) gradient. Data is shown as picogram drug transport per min to the receiver chamber over a total 120 min period. Results represent the mean \pm S.E.M. of triplicate samples.

Fig. 2.

Apical to basolateral ( $\square$ ) and basolateral to apical ( $\bullet$ ) transport for dexamphetamine, MDMA, MDEA and p-MA in CLEFF-9 (Caco-2) monolayers, with pH 7.4 on both sides of the monolayers during the study (solid lines) and with the presence of a pH 6.0 buffer in the apical chamber, providing a $\mathrm{pH} 6 \rightarrow 7.4$ gradient (dotted lines). Individual data points represent Data the mean \pm S.E.M. of triplicate measurements. 


\section{References}

Amphoux, A., Vialou, V., Drescher, E., Bruss, M., Mannoury La Cour, C., Rochat, C., Millan, M.J., Giros, B., Bonisch, H., Gautron, S., 2006. Differential pharmacological in vitro properties of organic cation transporters and regional distribution in rat brain. Neuropharmacology 50, 941-952.

Artursson, P., 1990. Epithelial Transport of Drugs in Cell Culture. I: A Model for Studying the Passive Diffusion of Drugs over Intestinal Absorbtive (Caco-2) Cells. J. Pharm. Sci. 79, 476-482.

Bailey, C., Bryla, P., Malick, A., 1996. The use of the Intestinal Epithelial Cell Culture Model, Caco-2, in Pharmaceutical Development. Adv. Drug. Del. Rev. 22, 85-103.

Bertelsen, K.M., Greenblatt, D.J., von Moltke, L.L., 2006. Apparent active transport of MDMA is not mediated by P-glycoprotein: a comparison with MDCK and Caco-2 monolayers. Biopharm. Drug. Dis. 27, 219-227.

Blackmore, C.G., Varro, A., Dimaline, R., Bishop, L., Gallacher, D.V., Dockray, G.J., 2001. Measurement of secretory vesicle $\mathrm{pH}$ reveals intravesicular alkalinization by vesicular monoamine transporter type 2 resulting in inhibition of prohormone cleavage. $\mathbf{J}$. Physiol. 531, 605-617.

Calhau, C., Martel, F., Hipolito-Reis, C., Azevedo, I., 2003. Effect of thiamine on 3H-MPP+ uptake by Caco-2 cells. Pharmacol. Res. 48, 579-584.

Crowe, A., Ilett, K.F., Karunajeewa, H.A., Batty, K.T., Davis, T.M., 2006. Role of P glycoprotein in absorption of novel antimalarial drugs. Antimicrob. Agents Chemother. $50,3504-3506$.

Crowe, A., Lemaire, M., 1998. In Vitro and In Situ Absorption of SDZ-RAD using a Human Intestinal Cell Line (Caco-2) and a Single Pass Perfusion Model in Rats: Comparison with Rapamycin. Pharm. Res. 15, 1666-1672.

Crowe, A., Teoh, Y.K., 2006. Limited P-glycoprotein mediated efflux for anti-epileptic drugs. J. Drug Target. 14, 291-300.

Crowe, A., Wong, P., 2004. pH dependent uptake of loperamide across the gastrointestinal tract: an in vitro study. Drug Dev. Ind. Pharm. 30, 449-459.

Fraga, S., Sampaio-Maia, B., Serrao, M.P., Soares-da-Silva, P., 2002. Regulation of apical transporter of L-DOPA in human intestinal Caco-2 cells. Acta. Physiol. Scand. 175, 103-111. 
Friedgen, B., Wolfel, R., Russ, H., Schomig, E., Graefe, K.H., 1996. The role of extraneuronal amine transport systems for the removal of extracellular catecholamines in the rabbit. N-S. Arch. Pharmacol. 354, 275-286.

Gan, L., Thakker, D., 1997. Application of the Caco-2 Model in the Design and Development of Orally Active Drugs: Elucidation of Biochemical and Physical Barriers Posed by the Intestinal Epithelium. Adv. Drug Del. Rev. 23, 77-98.

Grasset, E., Bernabeu, J., Pinto, M., 1985. Epithelial Properties of Human Colonic Carcinoma Cell Line Caco-2: Effects of Secretagogues. Am. J. Physiol. 248, C410-C418.

Han, D.D., Gu, H.H., 2006. Comparison of the monoamine transporters from human and mouse in their sensitivities to psychostimulant drugs. BMC. Pharmacol. 6, 6.

Hidalgo, I., Raub, T., Borchardt, R., 1989. Characterization of the Human Colon Carcinoma Cell Line (Caco-2) as a Model System for Intestinal Epithelial Permeability. Gastroenterology 96, 736-749.

Hosoya, K., Kim, K., Lee, V., 1996. Age-dependent Expression of P-Glycoprotein gp170 in Caco-2 Cell Monolayers. Pharm. Res. 13, 885-890.

Kanfer, I., Dowse, R., Vuma, V., 1993. Pharmacokinetics of oral decongestants. Pharmacotherapy 13, 116S-128S; discussion 143S-146S.

Ketabi-Kiyanvash, N., Weiss, J., Haefeli, W.E., Mikus, G., 2003. P-glycoprotein Modulation by the Designer Drugs Methylenedioxymethamphetamine, Methylenedioxyethylamphetamine and Paramethoxyamphetamine. Addict. Biol. 8, 413-418.

Kuwayama, K., Inoue, H., Kanamori, T., Tsujikawa, K., Miyaguchi, H., Iwata, Y., Miyauchi, S., Kamo, N., Kishi, T., 2008. Uptake of 3,4-methylenedioxymethamphetamine and its related compounds by a proton-coupled transport system in Caco-2 cells. Biochim. Biophys. Acta. 1778, 42-50.

Mann, H., Ladenheim, B., Hirata, H., Moran, T., Cadet, J., 1997. Differential Toxic Effects of Methamphetamine (METH) and Methylenedioxymethamphetamine (MDMA) in Multidrug-resistant (mdr1a) Knockout Mice. Brain Res. 769, 340-346.

Monteiro, R., Calhau, C., Martel, F., Faria, A., Mateus, N., Azevedo, I., 2005. Modulation of MPP+ uptake by tea and some of its components in Caco-2 cells. N-S. Arch. Pharmacol. 372, 147-152.

Partilla, J.S., Dempsey, A.G., Nagpal, A.S., Blough, B.E., Baumann, M.H., Rothman, R.B., 2006. Interaction of amphetamines and related compounds at the vesicular monoamine transporter. J. Pharmacol. Exp. Ther. 319, 237-246. 
Schomig, E., Lazar, A., Grundemann, D., 2006. Extraneuronal monoamine transporter and organic cation transporters 1 and 2: a review of transport efficiency. Handb. Exp. Pharmacol. 151-180.

Schwab, M.E., Thoenen, H., 1983. Mechanism of uptake and retrograde axonal transport of noradrenaline in sympathetic neurons in culture: reserpine-resistant large dense-core vesicles as transport vehicles. J. Cell. Biol. 96, 1538-1547.

Seithel, A., Karlsson, J., Hilgendorf, C., Bjorquist, A., Ungell, A.L., 2006. Variability in mRNA expression of ABC- and SLC-transporters in human intestinal cells: comparison between human segments and Caco-2 cells. Eur. J. Pharm. Sci. 28, 291-299.

Silvestrini, B., Palmery, M., Basta, F., Valeri, P., 1991. Facilitating effect of amphetamine on the response of rabbit aortic strips to adrenaline, dopamine and serotonin. $\mathrm{J}$. Neural.Transm. Gen. sect. 86, 51-59.

Soares, M., Carvalho, M., Remiao, F., Bastos, M., 2004. Simultaneous Determination of Amphetamine Derivatives in Human Urine after SPE Extraction and HPLC-UV Analysis. Biomed. Chromatogr. 18, 125-131.

Sulzer, D., Rayport, S., 1990. Amphetamine and other psychostimulants reduce pH gradients in midbrain dopaminergic neurons and chromaffin granules: a mechanism of action. Neuron 5, 797-808.

Till, A.E., Benet, L.Z., 1979. Renal excretion of pseudoephedrine in the rat. J. Pharmacol. Exp. Ther. 211, 555-560.

Tsuji, A., Tamai, I., 1996. Carrier-Mediated Intestinal Transport of Drugs. Pharm. Res. 13, 963-977.

Upreti, V.V., Eddington, N.D., 2008. Fluoxetine pretreatment effects pharmacokinetics of 3,4methylenedioxymethamphetamine (MDMA, ECSTASY) in rat. J. Pharm. Sci. 97, 1593-1605.

Wang, T.K., Fuh, M.S., 1996. Determination of amphetamine in human urine by dansyl derivatization and high-performance liquid chromatography with fluorescence detection. J. Chromatogr. B. Biomed. Appl. 686, 285-290.

Wu, X., Whitfield, L., Stewart, B., 2000. Atorvastatin Transport in the Caco-2 cell Model: Contribution of P-Glycoprotein and the Proton-Monocarboxylic Acid Co-Transporter. Pharm. Res. 17, 209-215.

Yamada, H., Yamahara, A., Yasuda, S., Abe, M., Oguri, K., Fukushima, S., Ikeda-Wada, S., 2002. Dansyl chloride derivatization of methamphetamine: a method with advantages for screening and analysis of methamphetamine in urine. J. Anal. Toxicol. 26, 17-22. 
Youdim, K., Dobbie, M., Kulhnle, G., Proteggente, A., Abbott, N., Rice-Evans, C., 2003. Interaction Between Flavonoids and the Blood-Brain Barrier: in vitro Studies. J. Neurochem. 85, 180-192.

Zhu, H.J., Wang, J.S., DeVane, C.L., Williard, R.L., Donovan, J.L., Middaugh, L.D., Gibson, B.B., Patrick, K.S., Markowitz, J.S., 2006. The role of the polymorphic efflux transporter P-glycoprotein on the brain accumulation of d-methylphenidate and damphetamine. Drug. Metab. Dispos. 34, 1116-1121. 